EGU2020-22337

https://doi.org/10.5194/egusphere-egu2020-22337

EGU General Assembly 2020

(c) Author(s) 2020. This work is distributed under

the Creative Commons Attribution 4.0 License.

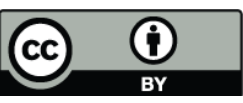

\title{
Weaker AMOC in coupled models inhibits north tropical Atlantic impact on ENSO
}

\author{
Belen Rodriguez-Fonseca ${ }^{1,2}$, Irene Polo ${ }^{1}$, Elsa Mohino ${ }^{1}$, Teresa Losada ${ }^{1}$, Marta Martín-Rey ${ }^{3}$, Noel \\ Keenlyside ${ }^{4}$, and C. Roberto Mechoso ${ }^{5}$ \\ ${ }^{1}$ Departamento de Física de la Tierra y Astrofísica, Facultad de Ciencias Físicas, Universidad Complutense de Madrid, Spain \\ ${ }^{2}$ Instituto de Geociencias IGEO (UCM-CSIC), Spain \\ ${ }^{3}$ Instituto de Ciencias del Mar (ICM, CSIC), Barcelona, Spain \\ ${ }^{4}$ University of Bergen (Norway) \\ ${ }^{5}$ University of California in Los Angeles (USA)
}

Observational studies have reported that interannual variability of sea surface temperature in two tropical Atlantic regions can act as ENSO predictors in different seasons and periods: boreal summer Atlantic Nino (AN) in negative phases of the Atlantic Multidecadal Variabil- ity (AMV); and boreal spring tropical north Atlantic (TNA) in positive AMV. The robustness of the AMV role in the interbasin connection remains an open question due to the short observational record. Using observations and pre-industrial climate model simulations, we demonstrate for the first time that latitudinal displacements of the Atlantic ITCZ act as a switch for the type of inter-basin teleconnection. During periods in which the Atlantic ITCZ is further equatorward (northward) AN (TNA) impacts ENSO. This ITCZ location can be 1 affected by several factors, including the interhemispheric SST gradients associated with AMV.Coupled models success in capturing the ANENSO connection. Nevertheless, they have difficulties in reproducing the TNA-ENSO connection because they overestimate rainfall in the southern tropical Atlantic. The TNA-ENSO connection occurs sporadically during periods when the ITCZ is shifted further northward in association with strong heat transports by the AMOC. Weaker AMOC periods in coupled models don't present the TNA-ENSO connection. State-of-the-art models still need to improve for correctly representing tropical Atlantic impact on ENSO. 